\title{
Role of Diffusion Weighted MRI in Characterization of Musculoskeletal Soft Tissue Tumors
}

\author{
HANA H. NASSEF, M.D.; AHMED M. BASSIOUNY, M.D. and MAHA A. QASSIM, M.Sc. \\ The Department of Radiology, Faculty of Medicine, A in Shams University
}

\begin{abstract}
Background: Magnetic Resonance Imaging is the method of choice for the diagnostic work-up of soft tissue tumors. It is the modality of choice to evaluate such masses, because of its excellent soft tissue contrast.

Aim of Study: To assess the efficacy of Diffusion weighted MRI in characterization of musculoskeletal soft tissue tumors.

Patients and Methods: The current study enrolled 20 patients (11 female and 9 male) with musculoskeletal STTs with mean age was $41.08 \pm 11.54$ year. The most frequent affected site with the swelling was the thigh $(48 \%)$ followed by the arm (20\%). Four (16\%) patients suffered from leg swelling while three $(12 \%)$ patients had shoulder swelling. Our results revealed that malignant musculoskeletal soft tissue masses had significantly lower ADC value in comparison to those with benign masses $\left(0.70 \pm 0.09\right.$ vs. $1.58 \pm 0.52 \times 10^{-3} \mathrm{~m}^{2} / \mathrm{s}$; $p<0.001)$.
\end{abstract}

Results: Patients with malignant lesions had significantly lower ADC value in comparison to those with benign lesions $\left(0.70 \pm 0.09\right.$ vs. $1.58 \pm 0.52\left(103 \mathrm{~mm}^{2} / \mathrm{s}\right)$. Myxoma had the highest ADC value that was $2.44\left(103 \mathrm{~mm}^{2} / \mathrm{s}\right)$ while sarcoma had lowest value that was $0.54 \pm 0.03\left(103 \mathrm{~mm}^{2} / \mathrm{s}\right)$. It was noticed that MRI had $100 \%$ sensitivity and $81.8 \%$ specificity for diagnosis of malignant musculoskeletal soft tissue masses with overall accuracy was $92 \%$ and area under curve was 0.91 at cut off value was $<1.14\left(103 \mathrm{~mm}^{2} / \mathrm{s}\right)$. Based on final diagnosis; MRI was successful in diagnosis of all cases with malignant musculoskeletal soft tissue masses but as the same time, MRI falsely diagnosed two cases with benign nature to be malignant. Those two cases were finally diagnosed to be lipoma.

Conclusion: Based on the current study, DWI-MRI considered the method of choice for the characterization of muscul oskel etal STTs; however, DW-MRI with ADC mapping is a rapidly, valuable, non-invasive, non-contrast tool for reliably differentiating between benign and malignant STTs. It's recommended to perform such study in large sample of patients and in more centers to confirm the great values of DWI-MRI in evaluation of such lesions.

Key Words: Diffusion weighted MRI - Musculoskeletal soft tissue tumors.

Correspondence to: Dr. Maha A. Qassim, E-Mail:mahaaalbaaj@yahoo.com

\section{Introduction}

MAGNETIC Resonance Imaging (MRI) is the method of choice for the diagnostic work-up of soft tissue tumors. The imaging characteristics of common benign lesions, such as lipoma and hemangioma, are often specific enough to allow a conclusive diagnosis. However, the imaging characteristics of a large number of soft tissue tumors are not diagnostic. Diffusion-weighted MRI have been mostly used for the diagnosis of early stroke, but applications in other fields such as oncological and musculoskeletal imaging are being explored [1].

MRI is the modality of choice to evaluate such masses, because of its excellent soft tissue contrast. Although there are some findings on MRI which are indicative for malignancy, such as infiltration of adjacent tissues, destruction of bones and tendons, and the size of the mass, there are no criteria available to clearly distinguish benign masses from malignancies [2] .

On the contrary, some very aggressive tumors present as an encapsulated mass without surrounding edema and only minimal contrast enhancement findings, which are in general indicative for benign processes. Thus, histopathologic work up is required for reliable characterization of soft tissue masses. As described DWI may reveal the microstructure of such masses and may therefore be helpful to distinguish [2].

The primary aim in soft tissue tumor imaging should be to reach a specific diagnosis or to narrow the differential diagnosis. This is to help decide whether biopsy, surgical intervention, or simple observation is required for further management, which leads to a cost effective method where we 
can reassure the patient and follow-up on the clearly benign lesions [3].

Functional and metabolic imaging techniques such as diffusion-weighted imaging (DWI) are available for clinical use and can potentially improve soft tissue tumor characterization. Visual analysis of DWI can detect lesions but is generally not used to characterize them. Quantitative DWI with apparent diffusion coefficient (ADC) analysis differentiates well between solid and cystic masses and ADC values have been reported to be significantly higher in benign musculoskeletal tumors than in malignant ones [4].

It has been reported that DWI has the potential to differentiate benign and malignant soft-tissue tumors because malignant tumors have greater cellularity and therefore have more restricted diffusion than benign tumors. Soft-tissue neoplasms are common tumors that have a large number of causes, arising from different categories of tumor types. Each is subdivided into benign, intermediate, and malignant subtypes $[\mathbf{5 , 6}]$

Conventional MR imaging is unable to offer information about the extent of tumoral necrosis and the presence of viable cells, information that is crucial for the assessment of treatment response and prognosis. Therefore, advanced MR imaging techniques, such as diffusion-weighted imaging (DWI), are now used in association with conventional MR imaging with the objective of improving diagnostic accuracy and treatment evaluation [7]

Aim of the work:

Aim of the study to assess the efficacy of diffusion weighted MRI in characterization of musculoskeletal soft tissue tumors.

\section{Patients and Methods}

\section{Study type and duration:}

A cross-section hospital based study was retrospectively conducted at Department of Radiology of Ain Shams University Hospitals. It was conducted over 6 months between May 2019 and October 2019.

\section{Inclusion criteria:}

- Any patient with musculoskeletal soft tissue tumors during the study period was enrolled.

\section{Exclusion criteria:}

- Pacemaker.

- Metallic foreign body in the eye.
- Cerebral aneurysm clips.

- Cochlear implant.

\section{Ethical consideration:}

The study was approved from The Ethical Committee of the Department of Radiology, Faculty of Medicine, Ain Shams University. Written consent was obtained from all participates before recruitment in the study after explanation of the purpose and procedures of the study.

\section{Study tools:}

All patients were subjected to complete history taking and examination. All MR imaging examinations were conducted at the Department of Radiology of the Ain shams University using 1.5 T closed MRI machine (ACHIEVA, PHILIPS) using the most optimal surface coil accommodates each lesion.

MRI system: The basic principle behind DWI is the stochastic Brownian motionorspecific diffusion of extra-cellular water molecules with in tissues. Diffusivity is represented by aquantitative variable, the ADC, which is the first line assessment method for DWI data. Diffusion the reforein directly reflects the histology of tissues (cellularity,but also fibrosis and hemoglobin degradation products, MR imaging is currently regarded as apivotal technique for the assessment of avariety of muscul oskeletal conditions. Diffusion-weighted MR imaging (DWI) is arelatively recent sequence that provides information on the degree of cellularity of lesions.

Apparent diffusion coefficient (ADC) value provides information on the movement of water molecules out side the cells. DWI has the potential to differentiate benign from malignants of ttissue tumors because malignant tumors have greate rcellularity with more restricted diffusion than benign tumors.

The predetermined examination protocol was applied to all patients that included the following: 1- T1-WI Axial (TR/TE=400-700/14-30; FOV, 2035 ) in axial, coronal and/or sagittal.

2- T2-WI (TR/TE=2800-4500/80-120; FOV, 2035 ) in axial, coronal and/or sagittal.

3- Post IV contrast sequences (including axial, sagittal and coronal) was applied to patients using gadolinium D.T.P.A with a calculated dose about $0.1 \mathrm{mmol} / \mathrm{kg}$ body weight, and at least one fat saturated sequence or short inversion recovery (STIR) sequence $(\mathrm{TR} / \mathrm{TE}=4000$ 5600/18-40; FOV, 20-35). 
4- Diffusion weighted MR images were acquired in the axial plane by single shot, spin-echo EPI sequence. The strength of MPG is defined by the gradient factor $\mathrm{b}$. The $b$-values used in this study were 0,400 and $800 \mathrm{~s} / \mathrm{mm}^{2}$.

Body parts being examined were immobilized to prevent motion artifacts, slice thickness ranged from $4 \mathrm{~mm}$ to $10 \mathrm{~mm}$, inter slice gap of $2-3 \mathrm{~mm}$, the matrix used for all sequences was $512 \times 256$ except the DWI which was $128 \times 64$.

Quantitative analysis was obtained by mathematically calculating the apparent diffusion coefficient (ADC). ADC maps are automatically generated by the workstation based on the three $\mathrm{b}$ values according to the formula $\mathrm{ADC}=\ln (\mathrm{S} 0 / \mathrm{S} 1) /$ (b1-b0), where S0 and S1 are the signal intensity before and after application of diffusion gradients, and $\mathrm{b} 1$ and $\mathrm{b} 0$ are the different $b$-values applied. The ADC is a numerical value calculated by manually placing a region of interest (ROI) over the solid portion of the tumor.

\section{Statistical analysis:}

We used SPSS version 15 (SPSS Inc., Chicago, IL, USA) for all analyses. Continuous data was expressed as mean and standard deviations while frequencies and percentages were calculated for qualitative variables.

Diagnostic performance of DW-MRI was evaluated against the pathology findings using the area under a receiver operating characteristic (ROC) curve and identifies a cut off value to diagnose malignancy. Based on the cut off value, a $2 \times 2$ contingency table was constructed and the sensitivity, specificity and accuracy were calculated. Level of confidence was kept at 955 and hence, $p<0.05$ was considered statistically significant.

\section{Results}

Age and sex of the patients $(n=20)$ :

Mean age of enrolled patients was $41.08 \pm 11.54$ years with range between 27 and 67 years. Out of the studied patients; 9 (44\%) patients were males and $11(56 \%)$ patients were females.

\section{Presentation among enrolled patients $(n=20)$ :}

The most frequent affected site with the swelling was the thigh (48\%) followed by the arm (20\%). Four (16\%) patients suffered from leg swelling while three (12\%) patients had shoulder swelling. One patient had swelling at the penis (Table 1).
It was noticed that $17(68 \%)$ patients had lesion with restricted diffusion and $8(32 \%)$ patients had lesion with fascilated diffusion. Majority (68\%) of the lesions were enhanced. Heterogenous lesion present in $19(76 \%)$ patients while only $4(16 \%)$ lesions had septation. Suppressed STIR was detected in 5 (20\%) patients. Based on MRI findings; $16(64 \%)$ lesion was malignant and $9(36 \%)$ lesion was benign (Table 2 ).

Based on histopathogical evaluation, 14 (56\%) patients had malignant lesions while 11 (22\%) patients had benign lesions. The most frequent benign lesions were lipoma (20\%) and hemangioma $(12 \%)$. Each myoma, adenoma, and leiomyoma present in one patient (Table 3).

Fibrosarcoma present in three (12\%) patients and also, sarcoma was detected in another three (12\%) patients. Two patients had melanoma. Each of small cell osteosarcoma, spindle cell carcinoma, squamous cell carcinoma, leiomyosarcoma, dermatofibrosarcoma and Ewing's sarcoma present in one patient (Table 3).

Based on the current study, it was noticed that malignant musculoskeletal soft tissue masses had significantly lower ADC value in comparison to those with benign masses $(0.70 \pm 0.09$ vs. $1.58 \pm 0.52$ $\left.\left(10^{-3} \mathrm{~mm}^{2} / \mathrm{s}\right) ; p<0.001\right)$. Myxoma had the highest ADC value that was $2.44\left(10^{-3} \mathrm{~mm}^{2} / \mathrm{s}\right)$ while sarcoma had lowest value that was $0.54 \pm 0.0310^{-3}$ $\mathrm{mm}^{2} / \mathrm{s}$ (Table 4).

It was noticed that MRI had $100 \%$ sensitivity and $81.8 \%$ specificity for diagnosis of malignant musculoskeletal soft tissue masses with overall accuracy was $92 \%$ and area under curve was 0.91 at cut off value was $<1.1410^{-3} \mathrm{~mm}^{2} / \mathrm{s}$ (Table 5).

Based on final diagnosis; MRI was successful in diagnosis of all cases with malignant musculoskeletal soft tissue masses but as the same time, MRI falsely diagnosed one case with benign nature to be malignant. This case was finally diagnosed to be lipoma (Table 6).

Table (1): Presentation among enrolled patients.

\begin{tabular}{ccc}
\hline & $\mathrm{N}=20$ \\
\hline Site of swelling: & & \\
Thigh & $12(48 \%)$ \\
Arm & 5 & $(20 \%)$ \\
Leg & 4 & $(16 \%)$ \\
Shoulder & 3 & $(12 \%)$ \\
Penis & 1 & $(4 \%)$ \\
\hline
\end{tabular}

Data expressed as frequency (percentage). 
Table (2): Characteristics of the lesions in magnetic resonance image.

\begin{tabular}{lccc}
\hline & $\mathrm{N}=20$ & & $\mathrm{~N}=20$ \\
\cline { 3 - 4 } & & & Histopathology: \\
Benign: & Lipoma & $3(15 \%)$ \\
Size (mm) & $100.14 \pm 79.87$ & Hemangioma & $1(10 \%)$ \\
& & Myxoma & $1(5 \%)$ \\
Diffusion: & & Adenoma & $1(5 \%)$ \\
Restricted & $17(68 \%)$ & Leiomyoma & $2(10 \%)$ \\
Fascilated & $8(32 \%)$ & Malignant: & $2(10 \%)$ \\
Enhancement & $17(68 \%)$ & Fibrosarcoma & $2(10 \%)$ \\
Heterogenous & $19(76 \%)$ & Malignant melanoma & $1(5 \%)$ \\
Septation & $4(16 \%)$ & Small cell osteosarcoma & $1(5 \%)$ \\
Suppressed STIR & $5(20 \%)$ & Spindle cell carcinoma & $1(5 \%)$ \\
Nature of mass: & & Squamous cell carcinoma & $1(5 \%)$ \\
Benign & $9(36 \%)$ & Leiomyosarcoma & $1(5 \%)$ \\
Malignant & $11(64 \%)$ & Dermatofibrosarcoma & $1(5 \%)$ \\
\end{tabular}

Data expressed as frequency (percentage), mean (SD).

Data expressed as frequency (percentage).

Table (4): ADC value among enrolled patients with musculoskeletal soft tissue mass.
Table (5): Accuracy of MRI in detection nature of musculoskeletal soft tissue mass.

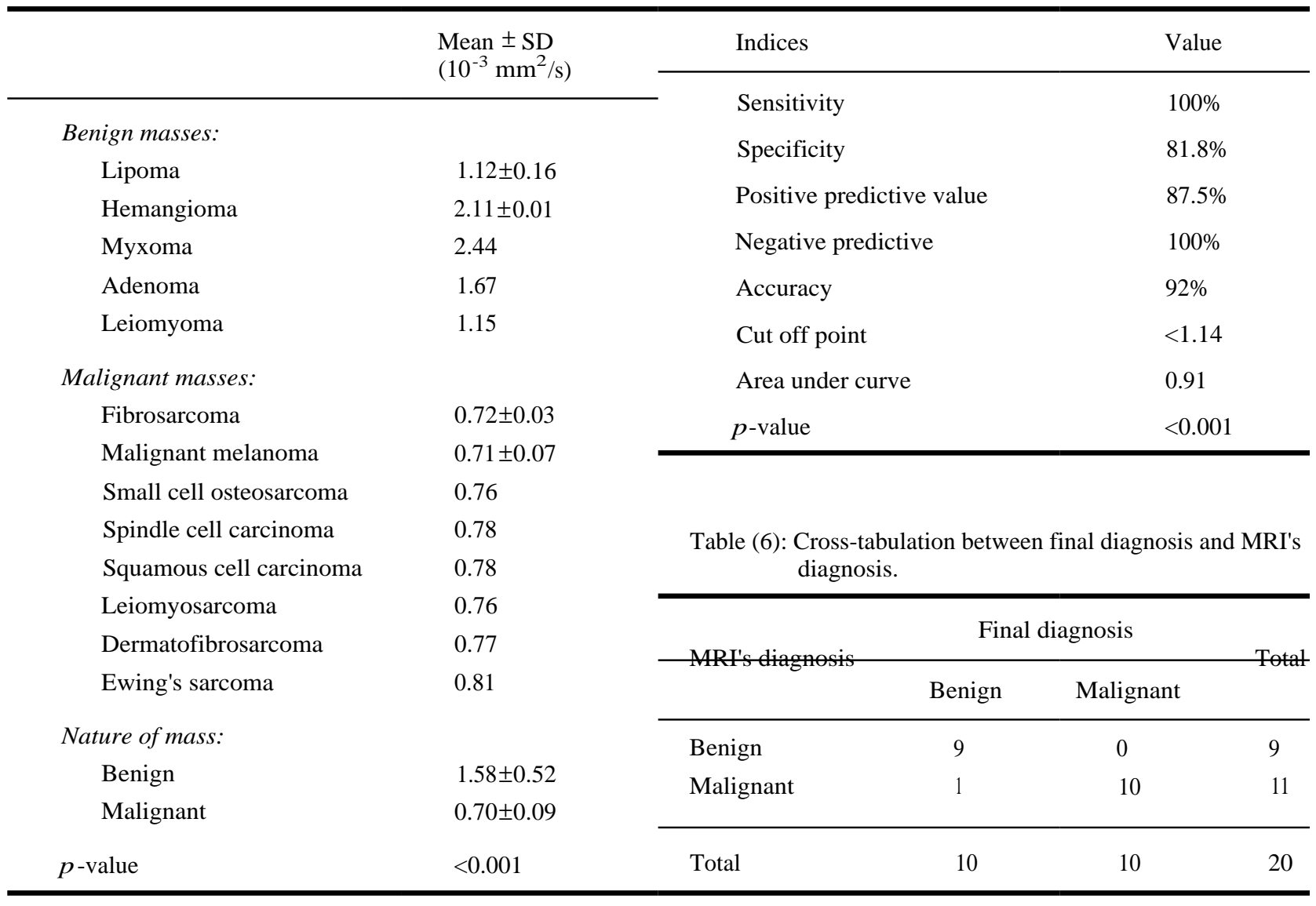

Data expressed as mean (SD).

$p$-value was significant if $<0.05$.

ADC: Apparent diffusion coefficient. 


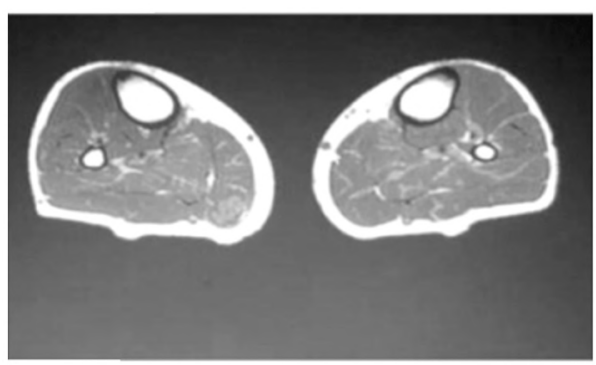

$\underline{\mathrm{T1}}$

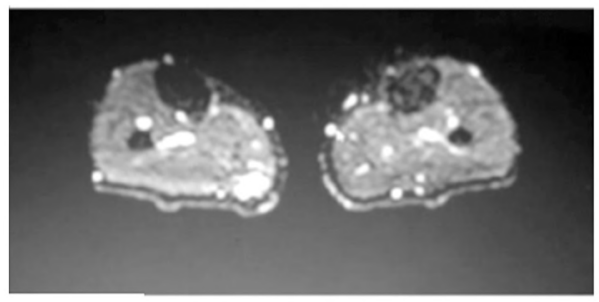

DWI

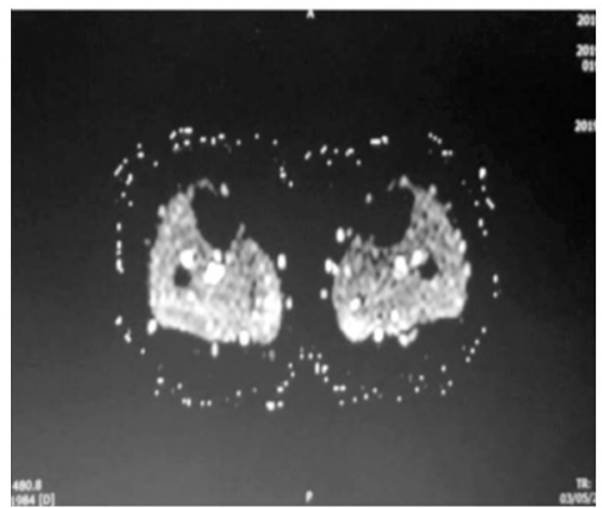

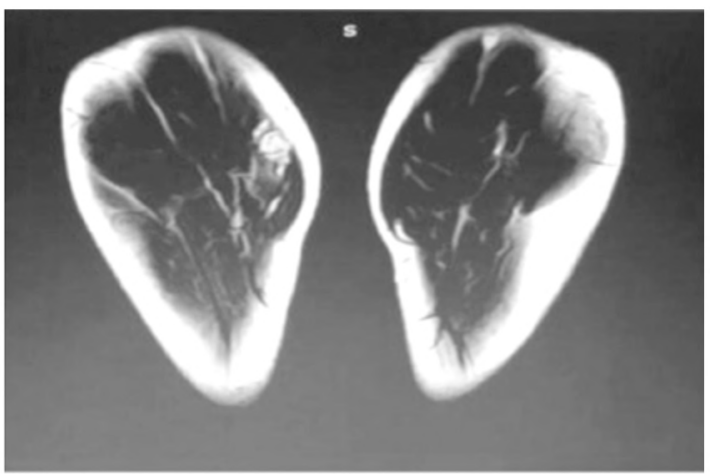

T2

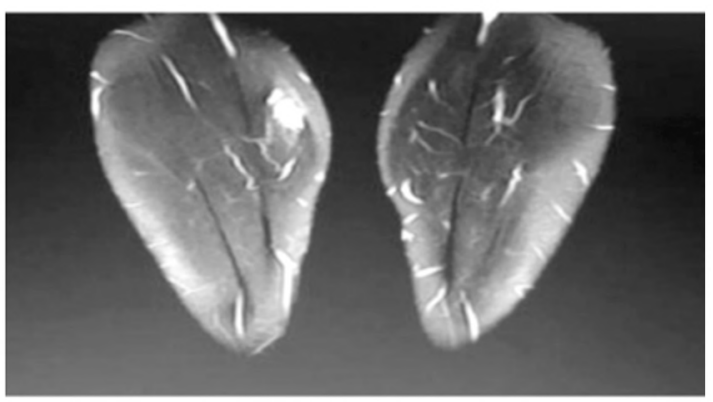

STIR

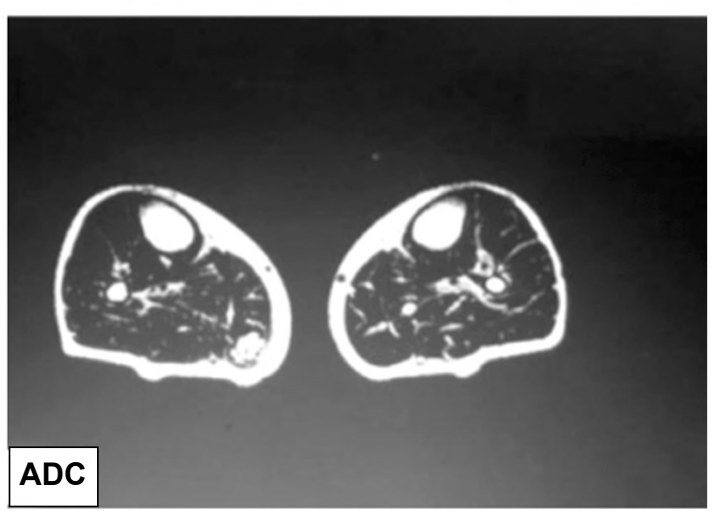

Fig. (1): Female patient aged 42 years old with haemangioma. MRI shows a well-defined rounded lobulated intramuscular soft tissue lesion at the upper third of the right leg within the medial head of right gastrocnemius muscle, it elicits bright signal in STIR and T2, faint hyperintense signal in T1. On DWI the lesion elicits high signals, with facilitated diffusion and ADC value $=2.13 \times 10^{-3} \mathrm{~mm}^{2} / \mathrm{sec}$.

\section{Discussion}

MRI is considered the modality of choice for evaluating soft tissue tumors (STTs) for diagnosis and characterization and for planning effective tumor management. DWI is a functional MRI technique and can be incorporated into routine MRI protocols with little additional scanning time, resulting in a non-invasive method for the evaluation of STTs based on their histological composition. DWI and ADC mapping rapidly produce quantitative information about STT cellularity without contrast administration [8].

In line with the current study, Romeih et al., [9] reported that mean ADC values of malignant STTs were significantly lower than those of benign
STTs. The mean ADC value of benign STTs was $1.43 \pm 0.56 \times 10^{-3} \mathrm{~m}^{2} / \mathrm{s}$, while that of malignant STTs was $0.74 \pm 0.18 \times 10^{-3} \mathrm{~m}^{2} / \mathrm{s}$; these values were significantly different $(p<.001)$.

Also, these results are consistent with those of Van Rijswijk et al., [10] who found that benign lesions have a mean ADC value of $1.71 \times 10^{-3}$ $\mathrm{mm} / \mathrm{s}$, which was significantly higher than that of malignant tumours $\left(1.08 \times 10^{-3} \mathrm{~mm}^{2} / \mathrm{s}\right)$ (van Rijswijk et al., 2002). Similarly, Neubauer et al., [11] reported ADC values of $0.78 \pm 0.45 \times 10^{-3}$ $\mathrm{mm}^{2} / \mathrm{s}$ and $1.71 \pm 0.7510^{-3} \mathrm{~m}^{2} / \mathrm{s}$ in malignant and benign tumours, respectively.

In a previously reported meta-analysis; Zou et al., [8] found that the ADC value is significantly 
lower in malignant soft-tissue tumor compared to benign tumor, suggesting that the ADC value has a vital significance in discriminating between malignant and benign tumor, and serve as an important tool for early diagnosis of soft-tissue tumors. Evidence from previous studies showed that the accuracy of DWI detection depends on the average $A D C$ values, which relates to tumor size and type and has been successfully employed to diagnose malignancies and to detect relapse in musculoskeletal tumors [8]

Restrictionofwater-molecule diffusion with in biological tissues correlates negatively with tissue cellularity and membrane eintegrity. Restrictionis greater in highly cellular issues that have in tactcell membranes and a small extra cellular compartment. Tumours differregarding their cellular characteristics, and the difference scan serve to differentiate tumour types [12]

Cellularity is greater in malignant tumours, in which restriction of water-moleculediffusion tends to be greater, compared to benign tumours. Highly cellularsites with restricted diffusionhave lower ADC values compared to site scharacterized by lower celldensities. Site swith low ADC values generate higher signalintensity on diffusion images [12].

The most frequent malignant lesions in the current study were sarcoma and fibrosarcoma. Each of them present in three patients with mean ADC value was $0.54 \pm 0.03$ and $0.72 \pm 0.03 \times 10^{-3}$ $\mathrm{m}^{2} / \mathrm{s}$. Also, Romeih et al., [9] reported that the most common malignant lesion was rhabdomyosarcoma ( 8 cases), which was characterized by low ADC values with a mean of $0.78 \pm 0.25 \times 10^{-3} \mathrm{~mm}^{2} / \mathrm{s}$. Six cases of synovial sarcoma (the second-most common malignant lesions) were included in this study with a mean $\mathrm{ADC}$ value of $0.77 \pm 0.21 \times 10^{-3}$ $\mathrm{mm}^{2} / \mathrm{s}$.

In agreement with the current study, recently performed study reported that four cases with myxoid sarcoma had high ADC values $2.30 \pm 0.28$ $\mathrm{x} 10^{-3} \mathrm{~mm}^{2} / \mathrm{s}$, which we considered false negatives [9].

Nagata et al., [13] found that myxoid-containing and non-myxoid tumours had ADC values 1.92 \pm $0.41 \times 10^{-3} \mathrm{~mm}^{2} / \mathrm{s}$ and $0.97 \pm 0.33 \times 10^{-3} \mathrm{~mm}^{2} / \mathrm{s}$, respectively $(p<0.01)$ (Nagata et al., 2008). Maeda et al., also reported significantly higher ADC values in myxoid tumours $\left(2.08 \pm 0.51 \times 10^{-3} \mathrm{~mm}^{2} / \mathrm{s}\right)$ than in non-myxoid tumours $\left(1.13 \pm 0.40 \times 10^{-3} \mathrm{~mm}^{2} / \mathrm{s}\right)$, high ADC value in malignant tumor lead to false negative result [5].
The most likely cause of increased diffusivity in myxoid-containing tumours is the abundance of free water in the myxoid matrix, which lead to highest ADC values, directly reflecting the low collagen and high mucin content of these lesions as well as the large amount of extracellular water seen histologically [14]

Also, in previously reported studies compared between myxoid and non-myxoid tumor containing as regard $\mathrm{ADC}$ value revealing that $\mathrm{ADC}$ values are relatively low in several non-myxoid malignant tumours, such as undifferentiated high-grade pleomorphic sarcoma, Ewing's sarcoma, malignant peripheral nerve sheath tumours, and lymphoma. In contrast, myxoid-containing tumours, whether benign or malignant, exhibit significantly higher ADC values than non-myxoid tumours [15]

The current study enrolled 11 benign STSs. The most frequent lesions were lipoma and haemangioma with ADV values were $1.12 \pm 0.16$ and $2.11 \pm 0.01 \times 10^{-3} \mathrm{~mm}^{2} / \mathrm{s}$, respectively. This result was consistent with reported by Costa et al., [16] who found that haemangioma had higher ADC value $2.3 \times 10^{-3} \mathrm{~mm}^{2} / \mathrm{s}$. Also, Romeih et al., [9] encountered 22 benign soft-tissue lesions. The highest ADC values were observed in giant-cell tumours $\left(2.35 \times 10^{-3} \mathrm{~mm}^{2} / \mathrm{s}\right)$, haemangiomas $(2.10$ $\left.\times 10^{-3} \mathrm{~mm}^{2} / \mathrm{s}\right)$, and schwannomas $\left(1.9 \times 10^{-3}\right.$ $\left.\mathrm{mm}^{2} / \mathrm{s}\right)$.

Based on final diagnosis; MRI was successful in diagnosis of all cases with malignant musculoskeletal soft tissue masses but as the same time, MRI falsely diagnosed one case with benign nature to be malignant. This case was finally diagnosed to be lipoma where theses lesions had lower ADC value below the accepted cut point for malignant STSs $\left(1.12 \pm 0.16 \times 10^{-3} \mathrm{~mm}^{2} / \mathrm{s}\right)$.

These results were consistent with those of Dietrich et al., [17], who found overlap between malignant and benign STTs, such as in lipomas, where large amounts of fatty tissue led to restricted diffusion. In highly cellular lesions, the free diffusion of water is restricted, resulting in low ADC values. Cellular tissue disruption (for example in necrosis) allows free diffusion in all directions, resulting in high ADC values [18].

It was noticed that MRI had $100 \%$ sensitivity and $81.8 \%$ specificity for diagnosis of malignant musculoskeletal soft tissue masses with overall accuracy was $92 \%$ and area under curve was 0.91 at cut off value was $<1.14 \times 10^{-3} \mathrm{~mm} 2 / \mathrm{s}$. 
This result is consistent with Romeih et al., [9] who obtained the following values: Area under the ROC curve $=0.82$, a sensitivity of $83.3 \%$, a specificity of $72.7 \%$, and a PPV and NPP of $80 \%$. Also, Neubauer et al., [11] reported an area under the ROC curve of 0.89 with a specificity of $91 \%$ and a sensitivity of $90 \%$.

One of the main limitations of the current study is that enrolled small sample size. In addition to, another drawback to this study was sometimes ROI including small necrotic areas or tiny cysts which could lead to an underestimation the performance of ADC analysis.

\section{Conclusion:}

Based on the current study, DWI-MRI considered the method of choice for the characterization of musculoskeletal STTs; however, DW-MRI with ADC mapping is a rapidly, valuable, non-invasive, non-contrast tool for reliably differentiating between benign and malignant STTs. It's recommended to perform such study in large sample of patients and in more centers to confirm the great values of DWI-MRI in evaluation of such lesions.

\section{References}

1- EINARSDÓTTIR H., KARLSSON M., WEJDE J. and BAUER H.C.: Diffusion-Weighted Mri of Soft Tissue Tumours. European Radiology, 14: 959-963, 2004.

2- ANDREAS M., RINGL H. and MEMARSADEGHI M.: Diffusion Weighted Imaging in Osteoradiology Top Magn. Reson. Imaging, 18: 203-212, 2007.

3- AFONSO P.D. and MASCARENHAS V.: Imaging Techniques For The Diagnosis of Soft Tissue Tumors. Reports In Medical Imaging, 8: 63-70, 2015.

4- TEIXEIRA P.A.G., GAY F., CHEN B., ZINS M., SIRVEAUX F., FELBLINGER J. and BLUM A.: DiffusionWeighted Magnetic Resonance Imaging For The Initial Characterization of Non-Fatty Soft Tissue Tumors: Correlation Between T2 Signal Intensity and Adc Values. Skeletal Radiology, 45: 263-271, 2016.

5- MAEDA M., MATSUMINE A., KATO H., KUSUZAKI K., MAIER S.E., UCHIDA A. and TAKEDA K.: SoftTissue Tumors Evaluated By Line-Scan DiffusionWeighted Imaging: Influence Of Myxoid Matrix On The Apparent Diffusion Coefficient. Journal of Magnetic Resonance Imaging: An Official Journal of The International Society For Magnetic Resonance In Medicine, 25: 1199-1204, 2007.

6- MANASTER B.: Soft-Tissue Masses: Optimal Imaging Protocol and Reporting. American Journal of Roentgenology, 201: 505-514, 2013.
7- KOH D.-M. and COLLINS D.J.: Diffusion-Weighted Mri In The Body: Applications And Challenges In Oncology. American Journal of Roentgenology, 188: 1622-1635, 2007.

8- ZOU Y., WANG Q.-D., ZONG M., ZOU Y.-F. and SHI H.-B.: Apparent Diffusion Coefficient Measurements With Diffusion-Weighted Imaging for Differential Diagnosis of Soft-Tissue Tumor. Journal of Cancer Research and Therapeutics, 12: 864, 2016.

9- ROMEIH M., RAAFAT T., KHALAF M. and SALLAM K.: The Diagnostic Value Of Diffusion-Weighted Magnetic Resonance Imaging In Characterization of Musculoskeletal Soft Tissue Tumors. The Egyptian Journal of Radiology and Nuclear Medicine, 49: 400-407, 2018.

10- VAN RIJSWIJK C.S., KUNZ P., HOGENDOORN P.C., TAMINIAU A.H., DOORNBOS J. and BLOEM J.L.: Diffusion-Weighted Mri In The Characterization of SoftTissue Tumors. Journal of Magnetic Resonance Imaging: An Official Journal of The International Society For Magnetic Resonance In Medicine, 15: 302-307, 2002.

11- NEUBAUER H., EVANGELISTA L., HASSOLD N., WINKLER B., SCHLEGEL P.G., KÖSTLER H., HAHN D. \& BEER M.: Diffusion-Weighted Mri For Detection and Differentiation of Musculoskeletal Tumorous And Tumor-Like Lesions In Pediatric Patients. World Journal of Pediatrics, 8: 342-349, 2012.

12- DRAPÉ J.-L.: Advances In Magnetic Resonance Imaging Of Musculoskeletal Tumours. Orthopaedics \& Traumatology: Surgery \& Research, 99: S 115-S 123, 2013.

13- NAGATA S., NISHIMURA H., UCHIDA M., SAKODA J., TONAN T., HIRAOKA K., NAGATA K., AKIBA J., ABE T. and HAYABUCHI N.: Diffusion-Weighted Imaging of Soft Tissue Tumors: Usefulness of The Apparent Diffusion Coefficient For Differential Diagnosis. Radiation Medicine, 26: 287-295, 2008.

14- KIM H.S., KIM J.-H., YOON Y.C. and CHOE B.K.: Tumor Spatial Heterogeneity In Myxoid-Containing Soft Tissue Using Texture Analysis of Diffusion-Weighted Mri. Plos One, 12: E0181339, 2017.

15- SUBHAWONG T.K., JACOBS M.A. and FAYAD L.M.: Diffusion-Weighted Mr Imaging For Characterizing Musculoskeletal Lesions. Radiographics, 34: 1163-1177, 2014a.

16- COSTA F.M., FERREIRA E.C. and VIANNA E.M.: Diffusion-Weighted Magnetic Resonance Imaging For The Evaluation of Musculoskeletal Tumors. Magnetic Resonance Imaging Clinics, 19: 159-180, 2011.

17- DIETRICH O., RAYA J.G., SOMMER J., DEIMLING M., REISER M.F. and BAUR-MELNYK A.: A Comparative Evaluation of A Rare-Based Single-Shot Pulse Sequence for Diffusion-Weighted Mri of Musculoskeletal Soft-Tissue Tumors. European Radiology, 15: 772-783, 2005.

18- RAGHAVAN M.: Conventional Modalities and Novel, Emerging Imaging Techniques for Musculoskeletal Tumors. Cancer Control, 24: 161-171, 2017. 


\section{دور التصوير بالرنين المغناطيسى بطريقة الانتشار

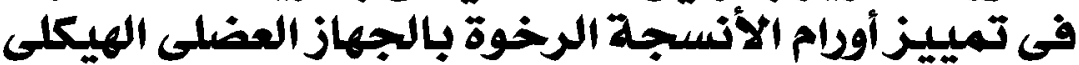

الخذفية: التصوير بالرنين المغناطيسى هو الطريقة المفضلة لتشخيص أودام الأنسجة الرخوة ويُعد ذلك بسبب التباين الممتاز للأنسجة

الهدف من الدراسة: تهذف هذه الدراسة إلى تقييم فعالية التصوير بالرنين المغناطيسى الموزونل لانتشار فى توصيف أورام الأنسجة

الرخوة العضلية الهيكلية.

المرضى وطرق البحث: شملت الدراسة الحالية 20 مريضاً ممن يعانون من أودام الأنسجة الرخوة فى العضلات والعات والعظام التقييم فعالية

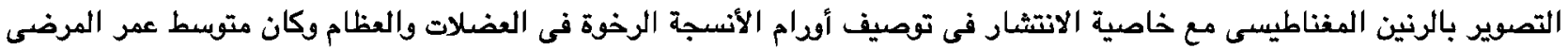

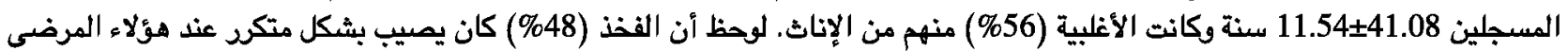

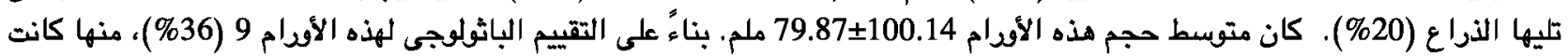

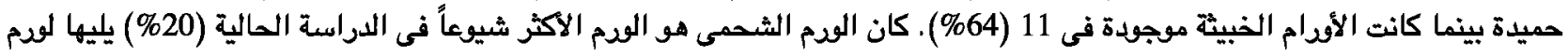
الوعائى الدموى (12\%).

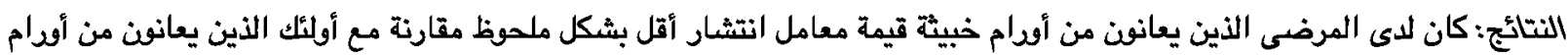

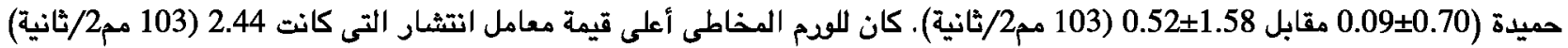

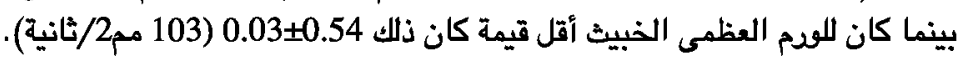

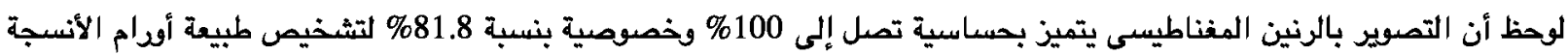

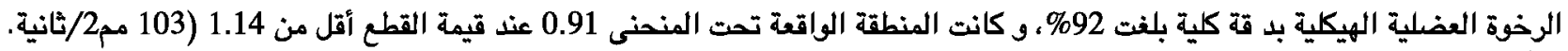

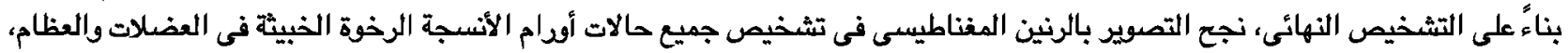

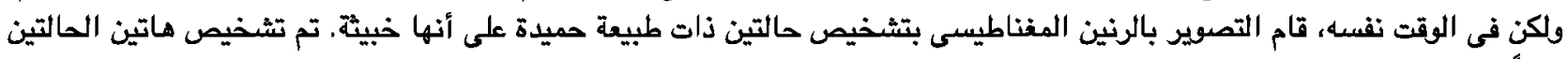

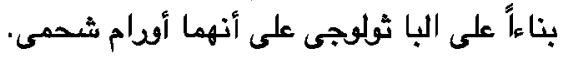

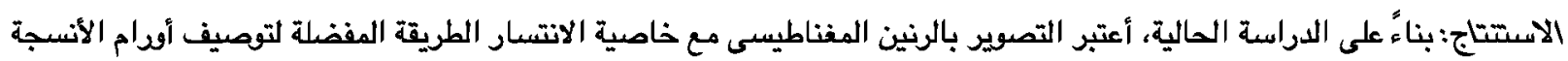

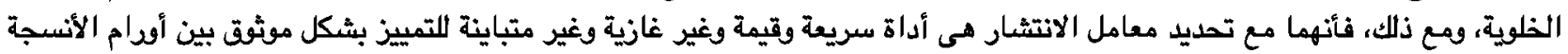

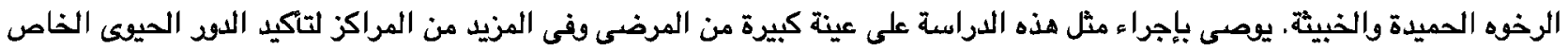

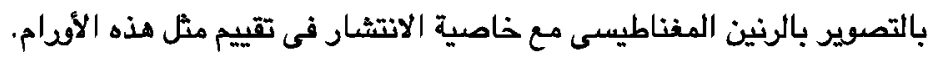

